\title{
Práticas exitosas em psicologia escolar: reflexões iniciais.
}

\section{Successful practices in school psychology: initial reflections.}

\author{
Jessica de Medeiros Possatto*, Claisy Maria Marinho-Araujo* \\ *Universidade de Brasília, Brasil.
}

\begin{abstract}
Resumo
As práticas exitosas em Psicologia Escolar rompem com concepções deterministas de desenvolvimento humano ao evidenciar o sucesso, enfocando as potencialidades em contraponto às dificuldades e limitações existentes no cotidiano educativo. $\mathrm{O}$ objetivo deste trabalho foi analisar e discutir práticas exitosas em Psicologia Escolar no atual cenário brasileiro. Verificou-se que tais práticas constituem-se em um importante indicador do perfil do psicólogo escolar que tem o seu olhar voltado para a cultura do sucesso e o compromisso crítico e reflexivo em seu campo de atuação. Destaca-se a importância da discussão e contribuição da Psicologia Escolar em eixos emergentes de atuação e pesquisa.

Palavras-chave: práticas exitosas; cultura do sucesso; psicologia escolar.
\end{abstract}

\section{Abstract}

Successful practices in School Psychology break with deterministic conceptions of human development by highlighting success, focusing on potentialities in counterpoint to the difficulties and limitations that exist in educational everyday. The objective of this work was to analyze and discuss successful practices in School Psychology in the current Brazilian scenario. It was verified that these practices constitute an important indicator of the profile of the school psychologist who has his eyes focused on the culture of success and the critical and reflexive commitment in his field of performance. We emphasize the importance of the discussion and contribution of School Psychology in emerging axes of action and research.

Keywords: successful practices; culture of success; school psychology.

\section{Práticas exitosas e a cultura do sucesso escolar}

A escola, lançada ao patamar de receptora universal, mantém sua contundente contradição: ao passo em que oscila entre o interesse e a tentativa de acolher pedagogicamente todos os estudantes, sucumbe à impossibilidade e impotência de alcançar tal proeza (Cunha \& Dazzani, 2016). Muito tem sido feito para que o sistema educativo incorpore todos os alunos em seus espaços, em vez de buscar selecionar os mais capazes e eliminar quem enfrenta dificuldade para aprender (Valle, 2003).

O psicólogo escolar tem, portanto, fundamental papel ao atuar junto aos processos que levam tanto à patologização da educação quanto ao discurso do sucesso escolar institucional.

Por muito tempo as práticas em Psicologia Escolar perpetuavam a cultura do fracasso escolar, onde os estudantes das chamadas minorias sociais não se sairiam bem na escola porque seu ambiente histórico-cultural dificultaria o desenvolvimento de competências necessárias a um bom desempenho escolar (Patto, 1990; 1992). A aplicação dos conhecimentos psicológicos na educação sem a reflexão necessária coadunava-se para que os processos de exclusão fossem reafirmados (Oliveira \& Marinho-Araujo, 2009).

A partir do avanço no campo de convergência entre a psicologia e educação, discussões e críticas se desdobraram em novos olhares tanto no conhecimento prático, quanto na formação de psicólogos escolares. Movimentações ocorreram (e vêm ocorrendo) afim de preconizar uma atuação que critique de práticas que possuem um viés adaptacionista e normatizador ao desenvolvimento humano. Oliveira \& Marinho-Araujo (2009) ressaltam a importância de abandonar as concepções e práticas que entendem os fenômenos educativos sobre o prisma individual e dissociado do contexto histórico-social no qual está inserido, devendo utilizar-se de concepções relacionais, integradoras e amplas. Guzzo (2015) ressalta que a presença do psicólogo na escola pode trabalhar para o exercício da liberdade, autonomia e expressão de sentimentos.

O termo práticas exitosas foi inspirado nas ações do Ministério da Educação (2006) como reconhecimento de experiências bem sucedidas, criativas e inovadoras. Libâneo (2015) analisa as ações bem-sucedidas em Psicologia Escolar como mediações que visam à partilha, com os atores educacionais, de reflexão, compromisso e implicação com a produção do sucesso escolar.

A cultura do sucesso escolar, em contraponto à culpabilização do aluno e da família pelo seu próprio fracasso, enfoca as potencialidades e possibilidades em vez dos problemas e dificuldades (Oliveira \& MarinhoAraujo, 2009). Libâneo (2015) discute que a atuação pautada no sucesso escolar exige um planejamento intencional da ação, além de um compromisso éticopolítico com a transformação de muitos.

As práticas exitosas em Psicologia Escolar podem ser entendidas como materialidades constituintes da atuação 
da cultura do sucesso (Libâneo, 2015). Tais práticas são marcadas pela intencionalidade na ação, com vistas à potencialização de uma educação crítica, transformadora, engajada social e politicamente.

Ter um olhar voltado para a cultura do sucesso é comprometer-se com uma Psicologia engajada no desenvolvimento de muitos, voltada para a ética social e institucional que perpassa as ações do psicólogo escolar em seu campo de pesquisa, formação e atuação.

Acreditando nas potencialidades que as práticas exitosas baseadas na cultura do sucesso trazem ao espaço escolar, este trabalho teve como objetivo discutir essas práticas em Psicologia Escolar no atual cenário brasileiro, convergindo com os estudos realizados em Portugal.

\section{O contexto de Brasil e Portugal com o foco em práticas exitosas}

Em pesquisa realizada por Libâneo (2015), foram caracterizadas as práticas exitosas que faziam parte da atuação de psicólogos da Secretaria de Educação do Distrito Federal. Entre os indicadores da cultura do sucesso que eram observados nas práticas, é interessante ressaltar a busca do profissional por reverter um processo de patologização do estudante, que recebeu ao longo dos anos diversos diagnósticos; e o psicólogo como mediador de processos de desenvolvimento humano adulto, possibilitando ao professor refletir sobre sua prática pedagógica e, especialmente, sobre suas concepções de desenvolvimento, aprendizagem, mediação e papel docente. Tais indicadores sinalizam para a atuação do psicólogo junto aos atores institucionais, potencializando as possibilidades de mediação.

Em relação às iniciativas públicas realizadas no cenário brasileiro que visam à disseminação de experiências bem-sucedidas, o Prêmio Professores do Brasil foi instituído em 2005 pelo Ministério da Educação (2006); essa iniciativa está em sua décima edição no ano de 2017. Ao longo desse período foram premiadas diversas experiências desenvolvidas por professores da educação básica na rede pública por serem consideradas bem sucedidas, criativas e inovadoras. Como objetivos, o prêmio visa reconhecer o trabalho dos professores das redes públicas como agentes fundamentais nos processos formativos e dar visibilidade às experiências pedagógicas consideradas exitosas, as quais sejam passíveis de adoção por outros professores e pelos sistemas de ensino.

Em 2015, o Ministério da Educação realizou uma chamada pública com o objetivo de criar bases para uma política pública de fomento à inovação e criatividade na educação básica. Para isso, foram selecionadas 178 instituições consideradas inovadoras e criativas, entre escolas e organizações não-governamentais que utilizavam-se de experiências de sucesso no que tange à gestão, currículo, ambiente, metodologia e intersetorialidade.

Dentre as instituições selecionadas, $74,3 \%$ são escolas e as outras $25,7 \%$ são organizações educativas que atuam na formação de crianças, adolescentes e jovens. Entre elas, $52,8 \%$ são públicas e 47,2\% são particulares. Em relação aos níveis de ensino, 83 instituições desenvolvem propostas com educação infantil, 132 trabalham com ensino fundamental, 73 estão voltada para o ensino médio e 40 atuam na educação de jovens e adultos.

Um ponto interessante é que no ensino médio há ocorrência de práticas exitosas tanto na modalidade regular quanto no ensino técnico.

Com o intuito de valorizar e divulgar as experiências educativas inovadoras de professores universitários dos cursos de Licenciatura, a Fundação Carlos Chagas (2015) lançou o Prêmio Professor Rubens Murillo Marques. O prêmio teve sua primeira edição em 2011, e ressalta a importância da qualidade da formação dos professores que atuam nos contextos educativos.

Em Portugal, o Ministério da Educação divulgou, em 2016, o Programa Nacional de Promoção do Sucesso Escolar (MEC, 2016), com o objetivo de apresentar e implementar planos de ação estratégica de promoção ao sucesso escolar nas escolas do ensino público. Em 2017, foi autorizada a realização de projetos-piloto de inovação pedagógica, como experiência durante três anos escolares com o objetivo de adotar medidas que promovam a qualidade das aprendizagens e permitam a eliminação do abandono e insucesso escolar em todos os níveis de ensino (MEC, 2017).

Tais iniciativas demonstram a importância do reconhecimento e implementação de práticas exitosas baseadas na cultura do sucesso escolar nos dois países, visto que há uma movimentação em ambos para mudança nos tradicionais processos de ensino. Considerando as semelhanças históricas entre as políticas educacionais que sustentam os sistemas de educação do Brasil e de Portugal, as iniciativas públicas atuais coadunam para que as transformações possam ocorrer em nível nacional.

Em relação à produção de conhecimento científico em Portugal, diversos autores têm voltado seus trabalhos à discussão da temática sucesso/insucesso escolar e práticas bem sucedidas englobando diferentes níveis de ensino e questionando o papel da escola na manutenção dessas concepções (Roazzi \& Almeida, 1988; Soares \& Almeida, 2003; Almeida, Guisande, Soares \& Saavedra, 2006; Ribeiro, Almeida \& Gomes, 2006; Bisinoto, Marinho-Araujo \& Almeida, 2010; Valadas, Araújo \& Almeida, 2014; Pacheco, 2016).

Soares, Almeida \& Primi (2014) relacionam como um desafio promissor à Psicologia a multidimensionalidade que o conceito de sucesso acadêmico permeia, assim como a compreensão das múltiplas variáveis que se articulam e cruzam nessa construção.

Bisinoto, Marinho-Araujo \& Almeida (2010) discutem que os serviços de apoio psicológico orientados à adaptação acadêmica e sucesso escolar dos estudantes apresentam-se como um espaço privilegiado de inserção da Psicologia Escolar no Ensino Superior. Visto que o Ensino Superior vêm oportunizando sua democratização no Brasil e em Portugal, cabe analisar se essa democratização ocorre mais como uma democratização de acesso do que uma real democratização do sucesso em relação ao que os frequentam (Soares \& Almeida, 2003).

Refletir, discutir e inovar as práticas em Psicologia Escolar permite que o acesso ao sucesso escolar seja democrático em diferentes níveis de ensino e contextos, reconhecendo suas diferenças e acreditando nas potencialidades. 


\section{A atuação preventiva como proposta à Psicologia Escolar}

Pautada em uma atuação do psicólogo escolar que promova a reflexão e conscientização de funções, papéis e responsabilidades dos sujeitos que atuam no cotidiano da escola, a atuação institucional preventiva é uma proposta que utiliza a intencionalidade no planejamento das ações do profissional, contribuindo e oportunizando aos atores envolvidos saltos qualitativos de desenvolvimento (Marinho-Araujo, 2010; MarinhoAraujo \& Almeida, 2014).

Essa proposta de atuação, caracterizada por uma intervenção dinâmica, participativa e institucional, é ancorada em quatro grandes dimensões: mapeamento institucional, espaço de escuta psicológica, assessoria ao trabalho coletivo e acompanhamento ao processo de ensino-aprendizagem (Araujo, 2003; Marinho-Araujo, 2010, 2015, 2016). Tais eixos permitem que a atuação do psicólogo seja estabelecida a partir das demandas reais e complexas que surgem no ambiente escolar considerada como uma instituição sociocultural, pautando-se em um olhar voltado para a cultura do sucesso.

A autora utiliza como base teórico-epistemológica para tal proposta a perspectiva histórico-cultural de desenvolvimento humano. Para ela entender o sujeito com base nessa perspectiva "pressupõe compreendê-lo constituído subjetivamente na própria história, desenvolvendo complexos processos de significados e sentidos que vão transformando tanto os processos sociais quanto os individuais" (Marinho-Araujo, 2016, pp. 52-53).

O psicólogo escolar, ao trabalhar mediações intencionalmente planejadas voltadas para todo o contexto educacional, de forma coletiva oportunizando vivências entrelaçadas na conscientização e subjetividade dos sujeitos, pode objetivar momentos de desenvolvimento para muitos no ambiente escolar (Marinho-Araujo, 2016).

Essa forma de atuação institucional permite à Psicologia Escolar se debruçar nas reais demandas que emergem no contexto escolar com o olhar voltado para as potencialidades dos sujeitos envolvidos, favorecendo a disseminação de práticas exitosas por toda a equipe institucional.

\section{Considerações finais}

Discutir as práticas exitosas tem se tornado um campo profícuo de pesquisa em Psicologia Escolar por disseminar experiências bem-sucedidas e inovadoras na educação básica e superior. Tais práticas constituem-se em um importante indicador de um perfil do psicólogo escolar que tem o seu olhar voltado para a cultura do sucesso e o compromisso crítico e reflexivo em seu campo de atuação.

É importante lembrar que, como discute Martín-Baró (1996), o saber mais importante do ponto de vista psicológico não é o conhecimento explícito e formalizado, mas esse saber inserido na práxis cotidiana, na maioria das vezes implícito, o qual permite a conscientização dos atores no ambiente educativo. Tal fato aponta para a importância do compromisso do psicólogo escolar com as reais e complexas demandas que surjem no espaço escolar como oportunidades para uma visão interagradora, ampla e relacional.

A atuação preventiva é uma proposta que, utilizandose da intencionalidade da ação, promove o caráter reflexivo aos atores institucionais e permite saltos qualitativos de desenvolvimento para os sujeitos envolvidos. As práticas exitosas com base na cultura do sucesso permitem avanços no conhecimento teóricoprático onde privilegia-se a autonomia dos atores escolares, valorizando as diferenças e reconhecendo a diversidade de formas de aprender, pensar e estar no mundo.

\section{Referências}

Almeida, L. S., Guisande, M. A., Soares, A. P., \& Saavedra, L. (2006). Acesso e Sucesso no Ensino Superior em Portugal: Questões de Género, Origem Sócio-Cultural e Percurso Académico dos Alunos. Psicologia: Reflexão e Crítica, 19(3), 507-514. Universidade Federal do Rio Grande do Sul, Porto Alegre - RS.

Araujo, C. M. M. (2003). Psicologia Escolar e o desenvolvimento de competências: Uma opção para capacitação continuada (Tese de doutorado não publicada). Universidade de Brasília, Brasília.

Bisinoto, C. Marinho, C., \& Almeida, L. (2010). Contribuições da psicologia escolar à promoção do sucesso acadêmico na educação superior. Seminário Internacional "Contributos da Psicologia em Contextos Educativos", pp. 102-114. Braga, Universidade do Minho. ISBN 978-972-8746-87-2.

Cunha, E. O, \& Dazzani, M. V. M. (2016). Da repulsa da escola à diferença: historicizando raízes, perspectivando saídas. In M. V Dazzani, V. L. T. Souza (Orgs.) Psicologia Escolar Crítica: Teoria e Práticas nos Contextos Educacionais. Campinas: Alínea.

Fundação Carlos Chagas. (2015). Prêmio Professor Rubens Murillo Marques. São Paulo - SP.

Guzzo, R. S. L. (2015). Escola amordaçada: Compromisso do psicólogo com este contexto. In A. M. Martínez (Ed.), Psicologia Escolar e Compromisso Social (pp. 17-29). Campinas, SP: Alínea.

Marinho-Araujo, C. M. (2010) Psicologia Escolar: Pesquisa e Intervenção. Em Aberto, 23, 15-35.

Marinho-Araújo, C. M. (2015). Psicologia Escolar na Educação Superior: novos cenários de intervenção e pesquisa. In C. M. Marinho-Araújo (Org.), Psicologia Escolar: novos cenários e contextos de pesquisa, formação e prática (2a ed.) (pp. 133-173). Campinas: Alínea.

Marinho-Araujo, C. M. (2016). Perspectiva históricocultural do desenvolvimento humano: fundamentos para atuação em Psicologia Escolar. In M. V Dazzani, V. L. T. Souza (Orgs.) Psicologia Escolar Crítica: Teoria e Práticas nos Contextos Educacionais. Campinas: Alínea.

Marinho-Araujo, C.M., \& Almeida, S. F. C. (2014). Intervenção institucional: possibilidades de prevenção em psicologia escolar. Psicologia Escolar: construção 
e consolidação da identidade profissional. Campinas: Alinea.

Martín-Baró, I. (1996). O papel do psicólogo. Estudos de Psicologia (Natal), 2, 7-27.

Ministério da Educação. (2006). Prêmio Professores do Brasil 2005. Brasília, Brasil.

Ministério da Educação. (2015). Portaria no 1.154 de 23 de dezembro de 2015. Inovação e Criatividade na Educação Básica. Brasília, Brasil.

Ministério da Educação. (2016). Programa Nacional de Promoção do Sucesso Escolar. Direção Geral da Educação. Lisboa - Portugal.

Ministério da Educação. (2017). Despacho n. ${ }^{\circ} 3721 / 2017$ - Diário da República n. ${ }^{\circ}$ 85/2017. Projetos-Piloto de Inovação Pedagógica (PPIP). Gabinete do Secretário de Estado da Educação. Lisboa - Portugal.

Oliveira, C. B. E., \& Marinho-Araújo, C. M. (2009). Psicologia Escolar: Cenários atuais. Estudos $e$ Pesquisas em Psicologia, 9(3), 648-663.

Pacheco, J. A. Organização curricular e pedagógica: uma conversação em torno do sucesso escolar. Texto para apoio pedagógico. Texto escrito no âmbito do Curso de Formação do lançamento do Programa Nacional de Promoção do Sucesso Escolar, Ministério da Educação, 2016.

Patto, M. H. S. (1990). A produção do fracasso escolar: Histórias de submissão e rebeldia. São Paulo: T. A. Queiroz.

Patto, M. H. S. (1992). A família pobre a escola pública: anotações sobre um desencontro. Psicologia USP, São Paulo, 3(1/2), 107-121.

Ribeiro, I. S., Almeida, L. S, \& Gomes, C. (2006) Conhecimento prévios, sucesso escolar e trajectórias de aprendizagem: do $1^{\circ}$ para o $2^{\circ}$ ciclo do ensino básico. Avaliação Psicológica, 5(2), 127-133.

Roazzi, A., \& Almeida, L. S. (1988) Insucesso escolar: insucesso do aluno ou insucesso do sistema escolar? Revista Portuguesa de Educação.

Soares, A. P., \& Almeida, L. S. (2003). Os Estudantes universitários: sucesso escolar e desenvolvimento psicossocial. In Mercuri, E. \& Soely A. J. Polyodoro (Orgs.) Estudante Universitário: Características $e$ experiências de formação Taubaté (pp.15-41). Cabral Editora e Livraria Universitária.

Soares, D. L., Almeira, L. S.,\& Primi, R. (2014). A convergência de variáveis pessoais e familiares na construção do sucesso acadêmico. Universidade do Minho. Instituto de Educação. Centro de Investigação em Educação.

Valadas, S. T., Araújo, A. M. D. C., \& Almeida, L. S. (2004). Abordagens ao estudo e sucesso académico no ensino superior. Revista Eletrônica de Psicologia, Educação e Saúde, 4(1), 47-67.

Valle, L. E. L. R. (2003). Psicologia Escolar: Um Duplo Desafio. Psicologia Ciência e Profissão, 23(1), 22-29.

\section{Agradecimentos}

Agradecemos especialmente o apoio da Fundação de Apoio à Pesquisa do Distrito Federal-FAPDF na possibilidade concreta da realização deste trabalho em âmbito internacional. 